\title{
A series of experiments on humour perception and memorization - a case of humour associations and remembering humorous stories
}

\author{
Stanislava Stoyanova \\ South-West University 'Neofit Rilski', Bulgaria \\ avka@abv.bg
}

\begin{abstract}
Four experiments with 48 participants were conducted to study humour perception and memorization. A computerized method (FVW) from Vienna Test System was used (Kessler, Pietrzyk \& Puhr, 2003), as well as humour associations, the recall of three funny stories, a short text evoking admiration and respect. The research was focused on what was associated with the word "humour" and on the types of the best remembered stories. The results indicated that the participants remembered better concrete rather than abstract stimuli, as well as meaningful rather than meaningless stimuli. The participants remembered well short verbal stimuli. They associated humour mainly with positive meaning, positive emotions (joy, happiness, amusement, satisfaction). The participants remembered better and nonintentionally the verbal stories heard by them that they estimated as the funniest compared to the stories estimated by them as less funny or the sentences provoking other positive emotions (admiration and respect). The funniest estimated stories were relevant to their personal experience, no matter if they contained puns or not. The estimated least funny story also contained puns, but contradicted some social norms related to the appropriate behaviour at the workplace.
\end{abstract}

Keywords: humour, memory, perception, experiment, positive emotions.

\section{Introduction}

Humour is a form of communication (Popescu, 2010; Taylor \& Raskin, 2012) by means of jokes, parody, farce, riddles, slapstick, satire, caricature and sarcasm (Apter \& Desselles, 2012, p.417, p.433). Humour may be perceived as oriented towards others or oneself, and it could be conductive or rather detrimental for one's well-being (Van den Broeck et al., 2012).

Humour may be perceived as a specific attitude towards others, self and events (Andreev, 2008) that could be affiliative (positive, other-focused humour), self-enhancing (positive, self-focused humour), self-defeating (negative, self-focused humour, detrimental for one's well-being), and aggressive (negative, other-focused humour) (Hall, 2013; Kuiper, 
2012; Malinowski, 2013; Sullivan, 2013; Martin et al., 2003; Dozois, Martin \& Faulkner, 2013; Ciieung \& Yue, 2013). Aggressive humour is perceived when people laugh at other people's infirmities (Popescu, 2010; Taylor \& Raskin, 2012).

Humour may also be perceived as an ability to laugh at oneself, to see the funny aspect of disagreeable situations (Bond, 1984; Bond \& Wesley, 1996), to create fun, amusement, laughter (Ciieung \& Yue, 2013: 351), and relief/release (Popescu, 2010; Taylor \& Raskin, 2012).

Sense of humour is attributed to an extraverted and intelligent person (Koppel \& Sechrest, 1970). A person is perceived as having a sense of humour if others laugh at what he/she did; if he/she laughs a great deal and is easily amused; and if he/she tells funny stories and amuses others (in Martin \& Sullivan, 2013: 376). A sense of humour is widely viewed as beneficial for health (Edwards \& Martin, 2012) and life satisfaction (Andreev, 2008).

Humour perception could be focused on incongruity - humour arises from violation of an expectation like the mismatch between two ideas (Popescu, 2010; Taylor \& Raskin, 2012). In disclosure humour, an identity (a person, a statement, etc.) is disclosed as having different characteristics/meanings from those originally supposed by the observer. In distortion humour, new characteristics are imaginatively added to the identity in a way that leads to absurdity. Disclosure humour takes something away, but distortion humour adds something (Apter \& Desselles, 2012). Related to these peculiarities is the perception of humour as reflecting creativity and social competence (Ciieung \& Yue, 2013).

Humour receives prolonged attention during information encoding (Strick et al., 2010) and humour is better memorized than other information (Summerfelt, Lippman \& Hyman, 2010).

Human mental processes and functions are interconnected. A series of experiments on humour perception and memorization could contribute to clarifying more factors that influence these phenomena than studying them separately. Humour studies could give evidence for interventions aiming to improve well-being and human interactions, as well as to enhance motivation for work or study.

Studying what types of content is perceived as humorous is important, because humour can contribute to enhancement of positive life experiences, happiness, greater positive affect (Izard, 1977; Kuiper, 2012; Savova, 2013; Veleva, 2005), and satisfaction with team task contributions and team integration (Sullivan, 2013).

\section{Research problems}

This study of humour perception was based on associations of the term "humour", as well as on relevance of past experience and correspondence of humorous content to some social norms. The study of humour memorization was focused on short-term memory and the different types of content.

\subsection{Hypothesis 1}

Humour would be associated mainly with positive meaning and positive emotions.

Humour is associated with word meaning and is evoked by specific words (Taylor \& Raskin, 2012). Emotionally arousing elements further enhance the memory effects of humorous material (Martin, 2010). 


\subsection{Hypothesis 2}

The funniest stories would be remembered better incidentally (non-intentionally) compared to the stories estimated as less funny. The stories perceived as the funniest ones would be relevant to one's personal experience. The story that is perceived as the least funny would contradict some social norms.

Relevant information facilitates encoding and retrieval (Krishnan \& Chakravarti, 2003). Relevance could be related to personal experience, social group membership, social norms, etc.

The oral presentation of information was chosen because of it being widespread in everyday situations. Paper-and-pencil and web-based administration formats through a humour survey did not differ significantly (Wang et al., 2013). The oral presentation of information should not influence the re-production of the funny stories.

A non-comedian told the funny stories. People find jokes delivered by comedians to be significantly more amusing (Johnson \& Mistry, 2013). When people are told to expect humorous material, the humour effect on memory still emerges (Carlson, 2011).

\subsection{Hypothesis 3}

The funny stories would be remembered better incidentally than some stories provoking other positive emotions (admiration and respect).

Humorous information is easily recalled, at higher rates than non-humorous information encoded in close temporal proximity (Carlson, 2011; Martin, 2010; Strick et al., 2010). Humorous content could be recalled after a substantial delay, for example about a 15 -week delay (Worthen \& Deschamps, 2008).

\section{Method}

A series of experiments was conducted to study perception and memorization of different humorous and positive content-provoking other positive emotions like admiration and respect.

All experiments were related and conducted as a sequence in order for the peculiarities of perception and memorization of humorous content to be differentiated from perception and memorization of other content provoking positive emotions. The ability to memorize different kinds of stimuli was specified. Dependency of perception and memorization of humorous content on some social norms was also studied.

The method of laboratory experiment was used.

A series of experiments were carried out in May 2013 with six groups of participants (2 groups were studied per day) in the Psychology laboratory in South-West University "Neofit Rilski" in Blagoevgrad, Bulgaria. Each group consisted of 8 subjects (at least 1 male subject, and not more than 3 men in a group). They knew each other well. In total, there were 48 university students (11 male and 37 female) from 21 to 39 years old, mean age $=23$ years old; $\mathrm{SD}=3.5$. They participated voluntarily.

\subsection{Pilot experiment}

A pilot experiment was conducted to study if the subjects who took part in the main series of experiments were able to correctly perceive, distinguish and memorize various stimuli. It was hypothesized that the participants would remember better concrete rather than abstract 
stimuli, as well as meaningful rather than meaningless stimuli; the participants would remember well short verbal stimuli.

In April 2013, 48 students were examined by a computerized test measuring memory FVW from Vienna Test System applicable to people aged 6 years and above.

FVW measures certainty of differentiating between familiar and new items. The test form S6 (100 items with a low level of difficulty; half of them verbal, the other half nonverbal; half of them concrete, the other half abstract; half of them meaningful, the other half meaningless) was given to the subjects. Cronbach's alpha lies between .78 and .86 depending on test form and sample (Kessler, Pietrzyk \& Puhr, 2003).

Sequences of words, objects, numbers, etc. were presented, and the respondent was required to decide for each item whether it was presented for the first or for the second time (a recognition task). The respondent was asked to work as fast and accurately as possible (Kessler, Pietrzyk \& Puhr, 2003).

The independent variable was the types of stimuli that could be verbal/non-verbal, concrete-abstract, meaningful-meaningless.

The dependent variable was the number of correctly perceived and memorized stimuli.

\subsection{Experiment 1}

This was an associative experiment (Jung, 1907), but some other authors call such technique the "test of words associations" (Bardin, 2003). This technique is called "experiment" in the classical Jung meaning, because not only word associations were recorded, but also time for giving them, as well as the peculiarities of non-verbal behaviour, such as laughter, exclamations, etc. Each participant had to say one association of the word "humour".

The independent variable was the personal meaning of "humour".

The dependent variable was the different types of associations to "humour".

\subsection{Experiment 2}

Three funny stories (Vitzovete, 2010: 21) were told to the groups of participants by the experimenter (a female non-comedian). Each story was told for less than 10 seconds (normal tempo of speaking). The three funny stories were said with the same intonation, neutrally.

One of the funny stories was related to work. A person shares that when s/he gets drunk, $\mathrm{s} /$ he does not have any force to work. S/he will have to stop ... working.

Another was related to sport. One box fighter had not been training for three days. His friends started to worry about him. He appeared on the third day and explained that he had arranged a puzzle for three days, but on the box it was written "From 3 to 5 years."

The third funny story was related to students. Several minutes before starting an exam, the professor asked if there were any questions. One student asked which course this exam was on (Vitzovete, 2010: 21).

The funny stories were told to each group of participants in a different order and all possible variations of the order of the funny stories were used - they were six in total.

Then each person was asked to vote for the funny stories - which s/he liked the most, and which s/he liked the least. After that, each participant was asked individually to repeat orally the funny stories that s/he had just heard.

A control group of 12 workers ( 6 male and 6 female), who had graduated only secondary education and who have worked for more than 10 years, were individually told the same funny stories and they arranged them from the funniest to the least funny one.

The independent variable was the content of the funny story related to past experience and/or pun. 
The dependent variables were perception of the stories as funny or not, and the degree of memorization of the stories.

\subsection{Experiment 3}

A short text related to the feelings of admiration and respect was told to the participants:"Bow before work! Bow before patience! Bow before knowledge! Bow before the skill!" (Kikioo, 2011: 1). "We all taken separately are different, but taken together are one whole." "

Then the participants were asked to repeat this text.

The independent variable was the content of the sentences related to positive emotions.

The dependent variable was the degree of memorization of the sentences.

The total series of experiments in May 2013 lasted about 60 minutes for each group of participants.

The experimental design was within-subjects design (Goodwin, 2004).

The data were statistically processed by means of SPSS 16 using descriptive statistics, Paired Sample T - Test and chi-square analysis. The effect sizes were calculated (Cohen $d$ ).

\section{Results}

\subsection{Results from the pilot experiment}

All participants memorized all types of stimuli well (concrete, abstract, verbal, non-verbal, meaningful and meaningless) - correctly (see Tables 1 and 2), and fast (see Table 3).

\begin{tabular}{|c|c|c|c|c|}
\hline \multirow{2}{*}{$\begin{array}{c}\text { Types of } \\
\text { stimuli }\end{array}$} & \multicolumn{2}{|c|}{ Best memorized by the participants } & \multicolumn{2}{c|}{ Worst memorized by the participants } \\
\cline { 2 - 5 } Concrete & $N$ & $\%$ & $N$ & $\%$ \\
\hline Abstract & 2 & 4.2 & 1 & 2.1 \\
\hline Verbal & 10 & 4.2 & 1 & 2.1 \\
\hline Non-verbal & 0 & 0 & 1 & 2.1 \\
\hline Meaningless & 0 & 0 & 10 & 20.8 \\
\hline Meaningful & 34 & 70.8 & 35 & 72.9 \\
\hline
\end{tabular}

Table 1. Best and worst memorized types of stimuli by the participants (in number and percentage of participants)

There was no subject who had any difficulties to remember a meaningful stimulus. After the meaningful stimuli, the verbal stimuli were memorized the best. No one respondent best memorized non-verbal or meaningless stimuli. Mainly, the meaningless stimuli were the worst memorized.

All participants well differentiated among the items presented once or repeatedly - the lowest index for Discrimination ability was 0.83 ; mean index for Discrimination ability was $0.9 ; \mathrm{SD}=0.04$. An index from 0 to 0.5 indicated a limited Discrimination ability.

A conservative answer tendency was indicated by 14 participants $(29.2 \%$ out of the sample answered "No" when they doubted if they had already seen the stimulus). Most participants $(\mathrm{N}=30 ; 62.5 \%)$ had a liberal answer tendency (they answered "Yes" when they doubted if they had seen the stimulus). 4 subjects demonstrated no clear answer tendency ( $8.3 \%$ had 0 as the index for Answer tendency); they used both strategies of answering when in doubt if they had already seen the stimuli. 


\begin{tabular}{|l|l|l|}
\hline Types of stimuli & $M$ & $S D$ \\
\hline Concrete & $90.1 \%$ & $8 \%$ \\
\hline Abstract & $78.6 \%$ & $11.3 \%$ \\
\hline Verbal & $87.6 \%$ & $8.9 \%$ \\
\hline Non-verbal & $80.8 \%$ & $10.7 \%$ \\
\hline Meaningless & $77.9 \%$ & $11.5 \%$ \\
\hline Meaningful & $90.3 \%$ & $7.7 \%$ \\
\hline
\end{tabular}

Table 2. Mean percentage of the correctly recognized types of stimuli

The respondents remembered the meaningful stimuli best, followed by the concrete stimuli, then the verbal stimuli, then the non-verbal stimuli, then the abstract stimuli, and the worst remembered were the meaningless stimuli.

The respondents remembered significantly more concrete stimuli than the abstract stimuli $\left(t_{|47|}=7.185 ; p<.001\right.$; Cohen $d=0.831-$ large effect size $)$, more concrete stimuli than the non-verbal stimuli $\left(t_{|47|}=6.864 ; p<.001\right.$; Cohen $d=0.696$ - medium effect size $)$, more concrete stimuli than the meaningless stimuli $\left(t_{|47|}=7.601 ; p<.001\right.$; Cohen $d=.871-$ large effect size).

The respondents remembered significantly more verbal stimuli than the non-verbal stimuli $\left(t_{|47|}=4.152 ; p<.001\right.$; Cohen $d=0.488-$ medium effect size $)$, more verbal stimuli than the abstract stimuli $(t|47|=6.939 ; p<.001$; Cohen $d=0.626$ - medium effect size $)$, more verbal than meaningless stimuli $\left(t_{|47|}=7.445 ; p<.001\right.$; Cohen $d=0.667$ - medium effect size).

The respondents remembered significantly more meaningful stimuli than the meaningless stimuli $\left(t_{|47|}=7.969 ; p<.001\right.$; Cohen $d=0.896$ - large effect size, more meaningful stimuli than the abstract stimuli $\left(t_{|47|}=7.582 ; p<.001\right.$; Cohen $d=0.856-$ large effect size), more meaningful stimuli than the verbal stimuli $\left(t_{|47|}=3.099 ; p=.003\right.$; Cohen $d$ $=0.229-$ small effect size $)$, more meaningful stimuli than the non-verbal stimuli $\left(t_{|47|}=\right.$ $7.249 ; p<.001$; Cohen $d=0.721$ - medium effect size).

\begin{tabular}{|l|l|l|}
\hline Types of stimuli & $M$ & $S D$ \\
\hline Concrete & 0.98 & 0.21 \\
\hline Abstract & 1.04 & 0.22 \\
\hline Verbal & 1.01 & 0.21 \\
\hline Non-verbal & 1.01 & 0.22 \\
\hline Meaningless & 1.05 & 0.22 \\
\hline Meaningful & 0.97 & 0.21 \\
\hline
\end{tabular}

Table 3. Mean time for correct recognition of the different types of stimuli (in seconds)

The respondents needed the shortest time to remember the meaningful and the concrete stimuli. They needed more time to remember verbal and non-verbal stimuli. The longest time was required for remembering the abstract and meaningless stimuli.

These results indicated that the participants remembered better concrete than abstract stimuli, as well as meaningful rather than meaningless stimuli. The participants remembered well short verbal stimuli.

\subsection{Results from Experiment 1}

All the associations of the word "humour" were given for 1-2 seconds. The given associations were "laugh" $(\mathrm{N}=8)$, "happy" $(\mathrm{N}=7)$, "to mock" $(\mathrm{N}=6)$, "joy" $(\mathrm{N}=6)$, "funny" 
$(\mathrm{N}=5)$, "happiness" $(\mathrm{N}=4)$, "entertainment" $(\mathrm{N}=2)$, amusing" $(\mathrm{N}=2)$, "disgrace" $(\mathrm{N}=1)$, "people" $(\mathrm{N}=1)$, "woman" $(\mathrm{N}=1)$, "parody" $(\mathrm{N}=1)$, "behaviour" $(\mathrm{N}=1)$, "smiles" $(\mathrm{N}=1)$, "knowledge" ( $\mathrm{N}=1)$, "satisfaction" $(\mathrm{N}=1)$.

There were no any answer-definitions, nor answers prolonged in time (Piriov, 1968). There were no missing answers. The associations were given fast which did not indicate any problems related to the experiences provoked by humour.

The nouns were 12 ( 1 of them in plural). The adjectives were 3 . Only 1 verb was used.

Only 3 associations of humour were concrete; the others were abstract.

\subsection{Results from Experiment 2}

All 48 students and 12 workers liked the funny stories in the following order: the one about the students was estimated as the funniest one, the one about the box fighter was put second, and the one about alcohol at work was estimated as the least funny story.

The students participating in the study repeated the funny stories estimated as humorous by them (about students' exam, and about the box fighter), but the students could not remember the funny story about drinking at work (only 2 of 48 students repeated this funny story $-\chi|1|^{2}=39.34 ; p<.001$ ). Two students even said that they had not understood the funny story about drinking.

The participants remembered incidentally two funny stories (each of them consisting of 7 and 5 sentences respectively) out of three.

\subsection{Results from Experiment 3}

The text related to the feelings of admiration and respect consisted of five sentences. All participants repeated the first sentence, the sentence about the knowledge from the end - "we are one whole". Three subjects repeated the part of the text "Bow before skill!" One participant repeated the part of the text "Bow before patience!" The participants remembered incidentally two full sentences provoking positive emotions of admiration and respect.

\begin{tabular}{|l|r|r|r|r|}
\hline & $M$ & $S D$ & $t \mid 47$ & $p$ \\
\hline $\begin{array}{l}\text { remembered sentences in the funny stories divided } \\
\text { into the total number of sentences }\end{array}$ & .74 & .05 & 23.4 & \multicolumn{1}{|c|}{} \\
\hline $\begin{array}{l}\text { remembered sentences provoking other positive } \\
\text { emotions divided into the total number of sentences }\end{array}$ & .52 & .07 & & \\
\hline
\end{tabular}

Table 4. Differences in memorization of the funny stories and the sentences provoking other positive emotions

The subjects remembered better the funny stories than the sentences expressing admiration and respect (see Table 4).

All participants shared that they felt well at the end of the series of the experiments and that they spent interestingly and usefully their time.

\section{Discussion}

Most people remember well information that has a sense for them, i.e. meaningful information (Stoyanova, 2011). The pilot experiment revealed that the participants had enough individual capacities for perception and memorization of different kinds of stimuli, 
especially concrete, meaningful and verbal stimuli. This was the basis for studying their perception and memorization of humorous information.

\subsection{Discussion of Experiment 1}

Hypothesis 1 was accepted. The participants associated the term "humour" mainly with words with positive meaning (10 out of 16 gave distinct associations), expressing positive emotions (joy, happiness, amusement, satisfaction).

North American participants associated humour with pleasant adjectives and seriousness with unpleasant adjectives. Chinese participants associated humour with unpleasant adjectives and seriousness with pleasant adjectives (in Martin \& Sullivan, 2013: 376). The findings for humour associations were the same in the Bulgarian sample as in the American sample.

Several associations of humour were related to human beings (people, woman). Gender is a special category with controversial findings regarding differences in humour use and humour direction. Some authors consider that humour production is greater in men than women (Martin \& Sullivan, 2013; Mickes et al., 2012). The findings from another study reveal that male participants used fewer humorous statements than female participants (Dunbar et al., 2012). Gender differences could depend on the type of humour.

Women used more often humour to decrease the impact of a criticism, to disparage themselves or compliment one's partner, and to establish similarity or connection with the partner. They also used light humour-puns, canned jokes, anecdotes, or playful comments. They preferred tension release humour, such as non-verbal humour-gesture, posture, or facial expression designed to ease tension or to make the partner laugh. They practiced laughing along -in response to something the partner said or did (Dunbar et al., 2012). Men in USA, Belgium and Hong Kong were significantly more likely to produce aggressive humour than women (in Martin \& Sullivan, 2013: 376). Women are less concerned than men with appearing witty and use humour primarily to create solidarity by highlighting similarity or shared experiences (Dunbar et al., 2012).

In the present experiment, when asked for more details, the association "woman" was used by a female participant with the meaning of "mocked at". In this case, humour communicates distinction and superiority (Friedman \& Kuipers, 2013). The participant took into account the accent on gender belonging to some types of humour, for example the funny stories regarding blond women.

One limitation of humour studies is related to the experimenter's gender that could relate the associations of humour to gender categorization.

The prevalence of nouns as associations is typical for young people (Batoeva, Popov \& Dragolova, 2006) as it was the case in this experiment, too.

\subsection{Discussion of Experiment 2}

The funny story about drinking at work is a kind of antisocial humour (earthy, i.e. transgressing social norms; Saroglou, Lacour \& Demeure, 2010). Humour is used by society to correct deviant behaviour, to sanction socially unacceptable behaviour (Popescu, 2010; Veleva, 2005). In the funny story about drinking, there is no idea of correction of wrong behaviour. Drinking at work is a negative phenomenon criticized and non-approved by society. The funny story that contradicted the social norms was the least remembered one. The other two funny stories were not related to infringement of social norms. The control group of workers also estimated as the least funny the story where the social norms of drinking before work/at work were disturbed. 
The subjects in the experimental group remembered the funny story related to their social status (as students) better. The funny story with the box fighter was also well remembered. It was related to sport and all participants in the study practiced some kinds of sport at university. Besides, one group of participants explained that they had personal experiences with a familiar box fighter. The participants remembered information related to their personal experience and occupation well. The order of presentation of the funny stories was not important for their remembering. Personal meaning of the information was relevant for its memorization.

The funny story about the box fighter corresponded to the social stereotype of sportsmen's low intellectual capacities and academic failures (Forster, 2012; Khan et al., 2012), but this stereotype was not supported by research findings (Gorman, 2010; Khan et al., 2012; Scheuer \& Mitchell, n.d.; Singh, 2011).

Hypothesis 2 was partly supported. The participants remembered better non-intentionally the verbal stories that they estimated as the funniest ones compared to the stories estimated by them as less funny. The funniest estimated stories were in some degree relevant to their personal experience. In the case of the control group of workers, they had not studied at university, but they had taken exams as pupils. A control group of sportsmen would also be useful, but most of them are also students. The story estimated as least funny may contradict drinking norms.

The limitations of this study are related to the fact that humour enhances memory for the gist of the material, but not for details such as exact wording (in Martin, 2010: 104). The participants could have preferred not to "discredit" themselves and they declared not being able to repeat the joke about drinking at work, i.e. the exact word order that contained the pun.

\subsection{Discussion of Experiment 3}

The participants repeated the information related to their occupation as well as the first sentence and the end of the last sentence. People can better retain the beginning and the end of information (in Gerganov, 1987; in Ruph, 2007).

Hypothesis 3 was accepted. The funny stories were remembered better non-intentionally than some stories provoking other positive emotions (admiration and respect). The participants remembered better the funny stories that had a concrete plot than abstract information that aimed to provoke and express admiration and respect.

Highly emotionally arousing and task-relevant stimuli are more likely to capture attention and they are better memorized than emotionally neutral items (Bergmann et al., 2012). Positive information is better memorized than neutral information (Khairudin et al., 2012).

These studies broadened the existing theories of humour perception and memorization suggesting that remembering humorous information better than non-humorous positive information may be due to concrete and meaningful verbal information, as well as positive associations of humorous content. This effect might be strengthened by the relevance of humorous content to personal experience and its correspondence to some social norms of the appropriate behaviour of some occupational groups.

\section{Future research directions}

Further research is necessary to reveal the effect of more types of humour and other positive emotions. 
This series of experiments contributes to clarify the relationship between humour and memory mediated by the characteristics of verbal information like its relevance to personal experience, concrete plot, puns, positive content, and correspondence to some social norms.

This study has some limitations related to the small number of participants, and their membership in the same social group (students), so future studies should focus on humour perception and memorization depending on relevance of humour content in different social groups and its correspondence to their social norms.

Humour perception depends on the societal norm in the setting (Gray \& Ford, 2013). Several previous studies have focused on cross-cultural differences in humour perception and humour preferences.

British attitudes toward humorous people are significantly more negative than Australians'. USA citizens report more frequent use of humour in social situations than British citizens. Hungarians prefer jokes featuring ethnic stereotypes more than English people do. Americans prefer and appreciate aggressive humour more than Belgians, Hong Kongers, Senegalese and Japanese participants do (Martin \& Sullivan, 2013: 375-376). More national peculiarities in preferred types of humour could be studied.

Some previous studies have also focused on perceptions of humour depending on norms in the workplace. For example, in a professional workplace setting, sexist jokes are perceived as more offensive than in a comedy club setting (Gray \& Ford, 2013). Sexist or racist humour in organizations has damaging effects (Westwood \& Johnston, 2013).

One research direction is to explore other norms, not only the drinking norm.

This series of experiments suggested that humorous content contradicting social norms for appropriate behaviour at work or conforming occupational stereotypes in the society may have influenced memorization of information. Future research could clarify if presenting nonoffensive humorous content that does not contradict social norms and are relevant to the tasks in occupational settings could make information easier to retrieve. Humour perception and memorization could also be studied in different occupational settings, such as teaching or advertising.

\section{Note}

${ }^{1}$ Pojelania za uchiteli [Wishes for teachers]. (2013). Retrieved May 2 $2^{\text {nd }}, 2013$ from http://pojelaniq-bg.net/pojelaniq-za-uchiteli.html

\section{References}

Andreev, B. (2008). 'Vrazka na chuvstvoto za humor s niakoi ot faktorite na subektivnoto blagopoluchie [Relation of sense of humour with some factors of subjective well-being]' Psihologichni izsledvania, 10 (1), pp. 169-178.

Apter, M. J. \& Desselles, M. (2012). 'Disclosure humor and distortion humor: A reversal theory analysis'. Humor: International Journal of Humor Research 25 (4), pp. 417-435.

Bardin, L. (2003). L'analyse de contenu [Content analysis], $11^{\text {th }}$ ed. Paris: PUF.

Batoeva, D., Popov, T. \& Dragolova, E. (2006). Pedagogicheska I psihologicheska diagnostika [Pedagogic and psychological diagnostics]. Sofia: Askoni-Izdat.

Bergmann, H. C, Rijpkema M., Fernandez, G., \& Kessels R. P. C. (2012). 'The effects of valence and arousal on associative working memory and long-term memory'. PLoS ONE, 7 (12: e52616), pp. 1-9. 
Bond, M. (1984). Defense Style Questionnaire (DSQ). Montreal: Department of Psychiatry at Sir Mortimer B. Davis - Jewish General Hospital.

Bond, M. \& Wesley, S. (1996). Manual for the Defense Style Questionnaire (DSQ). Montreal: Department of Psychiatry at Sir Mortimer B. Davis - Jewish General Hospital.

Carlson, K. A. (2011). 'The impact of humor on memory: Is the humor effect about humor?' Humor: International Journal of Humor Research 24 (1), pp. 21-41.

Ciieung, C.-K., \& Yue, X. D. (2013). 'Humor styles, optimism, and their relationships with distress among undergraduates in three Chinese cities'. Humor: International Journal of Humor Research 26 (2), pp. 351-370.

Dozois, D. J. A., Martin, R. A., \& Faulkner, B. (2013). 'Early maladaptive schemas, styles of humor and aggression'. Humor: International Journal of Humor Research 26 (1), pp. 97116.

Dunbar, N. E., Banas, J. A., Rodriguez, D., Liu, S.-J., \& Abra, G. (2012). 'Humor use in power-differentiated interactions'. Humor: International Journal of Humor Research 25 (4), pp. 469-489.

Edwards, K. R., \& Martin, R. A. (2012). 'Do humorous people take poorer care of their health? Associations between humor styles and substance use'. Europe's Journal of Psychology 8 (4), pp. 523-534.

Forster, J. (2012). Student-athletes and Academic Success. A Comparison of the Graduation Rates, GPA and After College Success of Student-athletes and Regular Students. Thesis. Albany, NY: The Honors College, University at Albany, State University of New York.

Friedman, S. \& Kuipers, G. (2013). 'The divisive power of humour: Comedy, taste and symbolic boundaries'. Cultural Sociology 7 (2), pp. 179-195.

Gerganov, E. (1987). Pamet I smisal [Memory and meaning]. Sofia: Nauka I Izkustvo.

Goodwin, C. J. (2004). Issledovanie v psihologii. Metod'i I planirovanie [Research in psychology. Methods and design], $3^{\text {rd }}$ edition. Sankt-Peterburg: Piter.

Gorman, D. A. (2010). The effect of Athletic Participation on Academic Achievement for High School Seniors in Eastern Tennessee. PhD Thesis. Lynchburg, VA: Faculty of the School of Education at Liberty University.

Gray, J. A. \& Ford, T. E. (2013). 'The role of social context in the interpretation of sexist humor'. Humor: International Journal of Humor Research 26 (2), pp. 277-293.

Hall, J. A. (2013). 'Humor in long-term romantic relationships: The association of general humor styles and relationship-specific functions with relationship satisfaction'. Western Journal of Communication 77 (3), pp. 272-292.

Izard, C. E. (1977). Human Emotions. New York: Plenum Press.

Johnson, A. J., \& Mistry, K. (2013). 'The effect of joke-origin-induced expectancy on cognitive humor'. Humor: International Journal of Humor Research 26 (2), pp. 321-341.

Jung, C. G. (1907). 'On psychophysical relations of the associative experiment'. Journal of Abnormal Psychology 1 (6), pp. 247-255.

Khairudin, R., Valipour, G. M., Nasir, R., \& Zainah, A. Z. (2012). 'Emotions as intermediaries for implicit memory retrieval processing: Evidence using word and picture stimuli'. Asian Social Science 8 (10), pp. 58-67.

Khan, M. Y., Jamil, A., Khan, U. A., \& Kareem, U. (2012). 'Association between participation in sports and academic achievement of college students'. International Journal of Academic Research in Business and Social Sciences 2 (8), pp. 419-431.

Kikioo. (2011). Kartichka "Pojelanie za uchiteli" [Greeting card "Wish for teachers"]. Retrieved May $2^{\text {nd }}, 2013$, from http://www.pozdravi.net/details.php?image $\mathrm{id}=11038$

Kessler, J., Pietrzyk, U., \& Puhr, U. (2003). Continuous Visual Recognition Task. Release 22.00. Mödling: Dr. G. Schuhfried Ges. M. b. H. 
Koppel, M. A., \& Sechrest, L. (1970). 'A multitrait-multimethod matrix analysis of sense of humour'. Educational and Psychological Measurement 30 (1), pp. 77-85.

Krishnan, H. S., \& Chakravarti, D. (2003). 'A process analysis of the effects of humorous advertising executions on brand claims memory'. Journal of Consumer Psychology 13 (3), pp. 230-246.

Kuiper, N. A. (2012). 'Humor and resiliency: towards a process model of coping and growth'. Europe's Journal of Psychology 8 (3), pp. 475-491.

Malinowski, A. J. (2013). 'Characteristics of Job Burnout and Humor among Psychotherapists'. Humor: International Journal of Humor Research 26 (1), pp. 117-133.

Martin, R. A. (2010). The Psychology of Humor: An Integrative Approach. Waltham, Massachusetts: Academic Press.

Martin, R. A., Puhlik-Doris, P., Larsen, G., Gray, J., \& Weir, K. (2003). 'Individual differences in uses of humor and their relation to psychological well-being: Development of the Humor Styles Questionnaire'. Journal of Research in Personality 37 (1), pp. 48-75.

Martin, G. N., \& Sullivan, E. (2013). 'Sense of humor across cultures: A comparison of British, Australian and American respondents'. North American Journal of Psychology 15 (2), pp. 375-384.

Mickes, L., Walker, D., Parris, J., Mankoff, R., \& Christenfeld, N. (2012). 'Who's funny: Gender stereotypes, humor production, and memory bias'. Psychonomic Bulletin \& Review 19 (1), pp. 108-112.

Piriov, G. D. (1968). Eksperimentalna psihologia [Experimental psychology]. Sofia: Nauka I izkustvo.

Popescu, C. (2010). 'Sociological perspectives on humour: Conflict theories and ethnic humour'. Buletinul Universităţii Petrol - Gaze din Ploieşti, 62 (1, Seria Filologie), pp. 3744.

Ruph, F. (2007). Guide to Reflective Thinking on University Learning Strategies: Actualizing my Intellectual Potential (3rd edition). Québec: Université du Québec en AbitibiTémiscamingue.

Saroglou, V., Lacour, C., \& Demeure, M.-E. (2010). 'Bad humor, bad marriage: Humor styles in divorced and married couples'. Europe's Journal of Psychology 6 (3), pp. 94-121.

Savova, S. (2013). Adaptivni strategii I samorealizatzia na studenti [Students' adaptive strategies and self-realization]. PhD thesis. Blagoevgrad: UI "Neofit Rilski".

Scheuer, L. J., \& Mitchell, D. (n.d.). 'Does physical activity influence academic performance?' $\quad$ Retrieved July $2^{\text {nd }}, \quad 2013$, from http://www.fmschools.org/webpages/twiniecki/files/Does\%20physical\%20activity\%20inf luence\%20academic\%20performance.pdf

Singh, R. (2011). 'Sports and academic achievement'. Retrieved July 2 $2^{\text {nd }}$, 2013, from http://www.yrdsb.edu.on.ca/pdfs/w/innovation/quest/journals/QuestJournal_RajeshSingh. pdf

Stoyanova, S. (2011). Experimentalna psihologia [Experimental psychology]. Blagoevgrad: UI "Neofit Rilski”.

Strick, M., Holland, R. W., Van Baaren, R., \& Van Knippenberg, A. (2010). 'Humor in the eye tracker: Attention capture and distraction from context cues'. Journal of General Psychology 137 (1), pp. 37-48.

Sullivan, P. (2013). 'Humor styles as a predictor of satisfaction within sport teams'. Humor: International Journal of Humor Research 26 (2), pp. 343-349.

Summerfelt, H., Lippman, L., \& Hyman, I. E. Jr. (2010). 'The effect of humor on memory: Constrained by the pun'. Journal of General Psychology 137 (4), pp. 376-394. 
Taylor, J. M., \& Raskin, V. (2012). 'On the transdisciplinary field of humor research'. Transactions of the SDPS: Journal of Integrated Design and Process Science 16 (3), pp. 133-148.

Van den Broeck, A., Elst, T. V., Dikkers, J., Lange, A. D. \& Witte, H. D. (2012). 'This is funny: On the beneficial role of self-enhancing and affiliative humour in job design'. Psicothema 24 (1), pp. 87-93.

Veleva, A. (2005). 'Znachenie na humora za sotzialnoto razvitie na deteto' [Meaning of humour for child's social development], in D. Zhelezarova \& Z. Krasteva (eds.), Prilozhna psihologia I socialna praktika [Applied psychology and social practice] Varna: UI "Tchernorizets Hrabar", pp. 365-372.

Vitzovete [The Funny Stories]. (2010). Newspaper Telegraph, 29.09.2010. p. 21.

Wang, C.-C., Liu, K.-S., Cheng, C.-L., \& Cheng, Y.-Y. (2013). 'Comparison of web-based versus paper-and-pencil administration of a humor survey'. Computers in Human Behavior 29 (3), pp. 1007-1011.

Westwood, R. I., \& Johnston, A. (2013). 'Humor in organization: From function to resistance'. Humor 26 (2), pp. 219-247.

Worthen, J. B., \& Deschamps, J. D. (2008). 'Humour mediates the facilitative effect of bizarreness in delayed recall'. British Journal of Psychology 99 (Pt 4), pp. 461-471. 